\title{
Investigation of Different Ionic Liquids in Improving Oil Recovery Factor
}

\author{
Ali Alarbah, Mohamed Shirif, Ezeddin Shirif \\ Petroleum Systems Engineering, Faculty of Engineering, University of Regina, Regina, Saskatchewan, Canada \\ Email: alarbaha@uregina.ca
}

How to cite this paper: Alarbah, A., Shirif, M. and Shirif, E. (2019) Investigation of Different Ionic Liquids in Improving Oil Recovery Factor. Advances in Chemical Engineering and Science, 9, 87-98. https://doi.org/10.4236/aces.2019.91007

Received: December 12, 2018

Accepted: January 20, 2019

Published: January 23, 2019

Copyright $\odot 2019$ by author(s) and Scientific Research Publishing Inc. This work is licensed under the Creative Commons Attribution International License (CC BY 4.0).

http://creativecommons.org/licenses/by/4.0/

(c) (i) Open Access

\begin{abstract}
In order to improve oil recovery, Enhanced Oil Recovery (EOR) techniques have been applied to several light and medium oil reservoirs. This research was directed towards the development of chemical flooding methods for such reservoirs. The main objective of this experimental work was to investigate the efficiency of introducing various types of Ionic Liquids (ILs), 1-Ethyl-3-methylimidazolium Chloride [EMIM][Cl],

1-Benzyl-3-methylimidazolium Chloride [BenzMIM][Cl], and Trihexyltetradecylphosphonium Chloride [THTDPh] [Cl] on the Recovery Factor (RF) of medium oil (Weyburn oil, $30.25 \mathrm{API}^{\circ}$ ) at room temperature. The series of flooding experiments were carried out by introducing a slug of IL mixtures. Results demonstrated that maximum oil recovery factor was obtained when [EMIM][Cl] was added in the displacing fluid. Further investigations have been conducted to examine the effect of ILs concentrations on the recovery mechanisms by measuring Surface Tension (SFT), pH, and viscosity of the displacing phases. Finally, the effect of theses ILs in wettability alteration was examined.
\end{abstract}

\section{Keywords}

Ionic Liquids, Weyburn Oil, Weyburn Produced Water, Surface Tension, Wettability Alteration

\section{Introduction}

Given the depletion of oil reservoir energy and the limited discovery of new reservoirs, petroleum researchers have begun seeking more efficient techniques; one of the most promising methods is Chemical Enhanced Oil Recovery (CEOR), which has been used over the last three decades. The entrapped oil can be recovered by introducing chemical fluids to the porous media to reduce the 
system's Interfacial Tension (IFT), increase the capillary number, maintain mobility control, decrease oil viscosity, and change reservoir wettability [1]. In recent times, chemicals called Ionic Liquids have been used to enhance the oil recovery factor.

Many studies have measured the properties of ionic liquids at different concentrations mixed either with water or other solvents. These investigations discovered that some ionic liquid types are capable of increasing mixture viscosity [2]. Kelkar and Maginn (2007) found that the effect of the ionic liquid on viscosity depends on its concentration in the mixture [3]. It has been concluded from Lafo et al. (2013) studies that the brine viscosity increases by adding Trihexyl phosphonium chloride ionic liquid, which reduces the mobility ratio between heavy oil and brine, and results in a higher oil recovery [4]. The effect of ILs on some surface behaviors such as surface tension has not yet been thoroughly studied as an aspect of enhanced oil recovery. Surface tension values are used as indications of surface interactions at the liquid interfacial microstructure [5]. To enhance the oil recovery process, it was observed that IFT increases as the concentration of salt in the aqueous phase increases. A small amount of chemical such as surfactant in the aqueous solution has the effect of decreasing the interfacial tension with salinity [6]. The Critical Micelle Concentration (CMC) is one of the critical surface activity parameters and at this concentration, the surfactant solution cannot reduce the IFT and the SFT any further [7] [8]. The CMC value can be determined either from measuring the IFT [9] or SFT [10].

Wettability is one of the major mechanisms that affect fluids flow in the reservoirs [11]. Limited studies have been carried out to demonstrate the effects of wettability alteration by ionic liquids. Bin-Dahbag et al. (2014) have done a series of flooding experiments on Berea sandstone samples by using different ionic liquids concentrations to investigate the wettability alteration [12]. It was concluded that ILs have the ability to shift the rock wettability from oil wet towards water wet as a result of the interaction between oil, rock, and IL [12]. A similar study was conducted by Mohammed and Babadagli (2016) to investigate the effect of several imidazolium ionic liquids to modify the wettability of oil-wet limestone and sandstone. Another study showed that ionic liquids were more efficient in changing the rock wettability than other surfacants [13].

Few studies have demonstrated the results of extracting more oil from consolidated and unconsolidated samples by using several ILs mixed with synthetic water or chemicals as tertiary recovery. Regarding core flooding experiments, Bin-Dahbag et al. (2014) found that the injection of a mixture of Ammonium-based IL with brine into a core sample for tertiary recovery increased the RF for medium crude oil (API $28.77^{\circ}$ ) by about 4.5 [\% OOIP] compared to low salinity solution flooding [12]. When compared to ammonium-based IL and brine mixtures, imidazolium-based IL mixed with brine and injected into a core sample as a tertiary recovery mode was able to extract 13 [\% OOIP] more [14]. Additionally, as a result of increasing ILs concentration in brine, the oil recovery factor 
from sandstone and carbonate reservoirs increases [15]. However, Alarbah et al. (2017) have found that the increase in the RF was not economical when the IL [EMIM][Ac] concentration rose beyond the optimum concentration [16].

In this research, flooding experiments were used to study the ability of introducing the $[\mathrm{EMIM}][\mathrm{Cl}]$, [BenzMIM] $[\mathrm{Cl}]$, and [THTDPh][Cl], at room temperature, various oil concentration mixed with Weyburn produced water into an unconsolidated sand pack. Moreover, the effect of IL on SFT, displacing phase viscosity, and $\mathrm{pH}$ were also measured for the IL mixtures. Finally, the impact of IL on wettability alteration was investigated.

\section{Experimental Work}

\subsection{Materials}

The oil sample used for the studies was taken from Weyburn crude oil with (30.25 $\mathrm{API}^{\circ}$ and $15.35 \mathrm{cP}$ ). The properties of the oil and the Saturates, Aromatics, Resins and Asphaltenes (SARA) fractions are presented in Table 1. Weyburn brine $(56,000 \mathrm{ppm})$ was used for the initial saturation of the sand-pack samples and flooding experiments. ([EMIM][Cl], $98 \mathrm{wt} \%),([B e n z M I M][C l], 97 \mathrm{wt} \%)$, and ([THTDPh] [Cl], $95 \mathrm{wt} \%)$ were used to investigate their efficiency on improving oil recovery factor). These chemicals were purchased from Sigma-Aldrich and used without any additional purification. The chemical structures of the employed ILs are shown in Figure 1. Also, different displacing fluids were made in the laboratory by mixing brine with the above mentioned chemicals that were later used in sand-pack flooding experiments, Table 2 shows the properties of aqueous solutions. Ottawa sand, 40 - 80 mesh, was used to prepare the unconsolidated sand-pack.

\subsection{Experimental Apparatus}

The apparatus used in this study consists of the following components:

Physical model: The physical model consisted of $18.75 \mathrm{~cm}$ steel core holder with $4 \mathrm{~cm}$ inner diameter.

Injection and pressure monitoring system: The conventional core flooding system was used with a $500 \mathrm{D}$ syringe pump to inject the fluids into the sand pack. The pump was connected to three transfer cylinders each with a floating piston with a capacity of $900 \mathrm{~cm}^{3}$ containing brine, or oil, or chemical mixtures. The pressure data for each experiment was measured with a Heise Pressure

Table 1. Properties of the Weyburn at $21.5^{\circ} \mathrm{C} \pm 1$.

\begin{tabular}{llc}
\hline Crude Oil Viscosity [cp] & & 15.35 \\
Oil Density $\left[\mathrm{gm} / \mathrm{cm}^{3}\right)$ & & 0.874 \\
Oil API $^{\circ}$ & & 30.25 \\
\hline & & 60.30 \\
SARA by Cenovus Energy Inc & Saturates & 24.10 \\
Composition & Aromatics & 10.50 \\
[wt\%] & Resins & 3.15 \\
\hline
\end{tabular}


Table 2. Properties of Aqueous Solutions.

\begin{tabular}{|c|c|c|}
\hline Displacing fluids & Viscosity $[\mathrm{cP}]$ & Density $\left[\mathrm{gm} / \mathrm{cm}^{3}\right]$ \\
\hline (Brine) & 1.017 & 1.066 \\
\hline (1000 ppm [EMIM] $[\mathrm{Cl}]+$ Brine $)$ & 1.341 & 1.073 \\
\hline$(2500$ ppm $[$ EMIM] $[\mathrm{Cl}]+$ Brine $)$ & 1.422 & 1.080 \\
\hline (1000 ppm [BenzMIM] $[\mathrm{Cl}]+$ Brine $)$ & 1.301 & 1.073 \\
\hline (1500 ppm [BenzMIM] $[\mathrm{Cl}]+$ Brine $)$ & 1.375 & 1.075 \\
\hline$(1000 \mathrm{ppm}[\mathrm{THTDPh}][\mathrm{Cl}]+$ Brine $)$ & 1.204 & 1.069 \\
\hline$(1500$ ppm $[$ THTDPh $][\mathrm{Cl}]+$ Brine $)$ & 1.213 & 1.072 \\
\hline
\end{tabular}

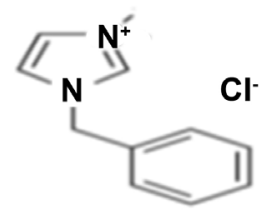

([BenzMIM][CI])

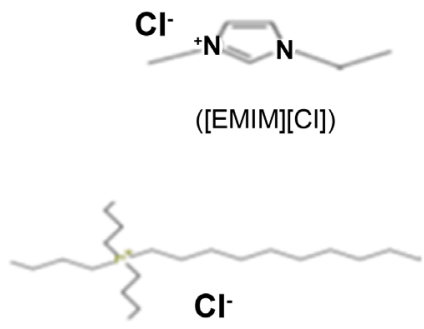

([THTDpH][Cl])

Figure 1. The Chemical Structures of Ionic Liquids.

Transducer, which calibrated the pressure drop across the core samples during the flooding process.

Production system: The core holder effluent was collected in $10 \mathrm{ml}$ glass tubes at atmospheric conditions $\left(101.325 \mathrm{kPa}\right.$ and $\left.21.5^{\circ} \mathrm{C} \pm 1^{\circ} \mathrm{C}\right)$. The oil and water were mixed at collection time and centrifuged through a Benchmark 2000 centrifuge.

Pores media and Displacing Fluids. By using sieve analysis, the average size of Ottawa sand was controlled at $40-80$ mesh. The displaced fluids' properties were measured by the subsequent apparatus. A digital weight meters quantified the digital masses of specific chemicals, which were added to the brine to prepare the displacing phases. Then, the solutions were stirred for 30 - 45 minutes at a speed of $120 \mathrm{rpm}$ to allow the IL solutions to mix adequately. The polymer solutions were stirred for $24 \mathrm{hrs}$ at $60 \mathrm{rpm}$. The viscosities of displacing fluids were measured by DV-II + Pro viscometer (supplied by Brookfield) with a temperature controller water-path. In order to measure the densities, the Anton Paar DSA $500 \mathrm{M}$ instrument was used. A KRUSS K100 device was utilized to measure the SFT of the displacing mixtures by using the Wilhelmy plate method; a Cole-Parmer water path was implemented to control the temperature). The $\mathrm{pH}$ and conductivity values of the displacing phases were measured with a $\mathrm{pH} / \mathrm{COND}$ Meter (supplied by HORIBA).

\subsection{Experimental Procedure}

A preparatory stage during which all apparatus were cleaned and calibrated was undertaken prior to research implementation. The following paragraphs describe in detail the preparatory stages: 
Packing Procedure: A vertically-oriented core holder was packed utilizing the dry-packing method, using (40 - 80 mesh) Ottawa sand with consistent sand size parts. The core sample was vibrated during the packing process to distribute, therefore making the sand grains uniform in the core holder. The sand-pack sample was $100 \%$ vacuumed by using vacuum pump for approximately $10 \mathrm{hrs}$ (until no bubble appeared); this step was preceded by packing the sand and fixing the cap after which the weight was measured. Subsequently, the model was connected to the pump and fully saturated with Weyburn brine. Then the porosity and the absolute permeability were calculated. The average petrophysical properties of the sand-pack samples are presented in Table 3.

Saturation Process. After finishing the routine core analysis, both the core holder and the core flooding system were connected vertically to determine the irreducible water saturation and the initial oil saturation, at a rate of $1 \mathrm{~cm}^{3} / \mathrm{min}$. The sand-pack flooded with medium oil until no free water seeped out from the core holder outlet. The total displaced brine represents the initial oil saturation $\left(\mathrm{So}_{\mathrm{i}}\right)$ while the remaining brine represents the irreducible water saturation $\left(\mathrm{Sw}_{\mathrm{i}}\right)$. The moment that the core sample was thoroughly saturated with oil, determined that the sand pack was ready for the flooding experiments.

Flooding Procedure: In this stage, the cores were positioned horizontally and flooded with either ILs, or polymer mixtures alone or ILs, and polymer mixture. For one of the scenarios the core samples were initially flooded with 1 pore volume of chemicals mixture then flushed by two pore volumes of brine. The optimum flow rate $\left(2 \mathrm{~cm}^{3} / \mathrm{min}\right)$ was applied as injection rate for flooding experiments that were done to investigate the effect of chemical concentration, the chemical solution slug size, the initiation time for injecting the chemical mixture as well as the flow rate that was obtained from previous study [16].

The produced oil and water samples from the sand pack were collected in graduated tubes and then placed in a separator to determine the exact amount of recovered oil. The total oil recovery factor was expressed as the ratio of produced oil to the original oil in place.

Subsequently, all the above-mentioned procedures were carried out at room temperature $\left(21.5^{\circ} \mathrm{C} \pm 1^{\circ} \mathrm{C}\right)$, and they all have been repeated with unused sand to ensure the consistency.

\section{Results and Discussion}

Effect of IL Type on RF: To test the effectiveness of ILs on the enhanced oil

Table 3. The average petrophysical properties of the sand-pack samples.

\begin{tabular}{cc}
\hline PV $\left(\mathrm{cm}^{3}\right)$ & $98.5( \pm 2)$ \\
So $(\%)$ & $83( \pm 1)$ \\
Ka (Darcy) & $5.2( \pm 0.5)$ \\
Swi (\%) & $17( \pm 1)$ \\
$\varnothing(\%)$ & $41( \pm 2)$ \\
\hline
\end{tabular}


recovery, different types of ionic liquids, [EMIM][Cl], ([BenzMIM][Cl]), and [THTDPh][Cl], were investigated by flooding IL mixtures at selected optimum concentration (1000 ppm), slug size (1 PV), and slug initiation time (as secondary mode) based on the data obtained from previous research [16]. The flooding for each core sample was per pore volume with one of ILs mixtures at the first stage, and later $2 \mathrm{PVs}$ of the brine flushed. As shown in Figure 2, the recovery factor curves rose dramatically with the injection of $1000 \mathrm{ppm}$ IL mixtures until the breakthrough. The breakthrough occurred when the samples were flooded with $1000 \mathrm{ppm}$ of [EMIM][Cl], [BenzMIM][Cl], and [THTDPh][Cl] mixtures for 0.417 PV, 0.401 PV, and 0.398 PV Injected, respectively. After the breakthrough, the recovery factors increase gradually and mainly depend on the Ionic Liquid type. The total RFs obtained from injecting 1000 ppm [EMIM][Cl], [BenzMIM] $[\mathrm{Cl}]$, and [THTDPh] $[\mathrm{Cl}]$ were 78.36 [\% OOIP], 75.01 [\% OOIP], and 75.15 [\% OOIP], respectively. However, the results that were obtained from using ILs mixtures in the flooding process were superior to those generated from injecting brine alone. The difference in oil recovery improvement could be due to the effect of Ionic Liquids on displacing phase viscosities, and surface tension as shown on Table 4.

Effect of IL Critical Micelle Concentration on RF. In order to determine the Critical Micelle Concentration (CMC) of ILs, the surface tension (SFT) was examined in displacing solutions at room condition. The CMC point that was obtained when [EMIM] [Cl] was added to brine was $2500 \mathrm{ppm}$ as shown in Figure 3. For the other two-studied ILs ([BenzMIM][Cl] and [THTDPh][Cl]), it was found that both of them have similar effectiveness in terms of reducing surface tension. The SFT values, as shown in Figure 4 and Figure 5, decrease when increasing the concentration of [BenzMIM][Cl] and [THTDPh][Cl] to $1500 \mathrm{ppm}$

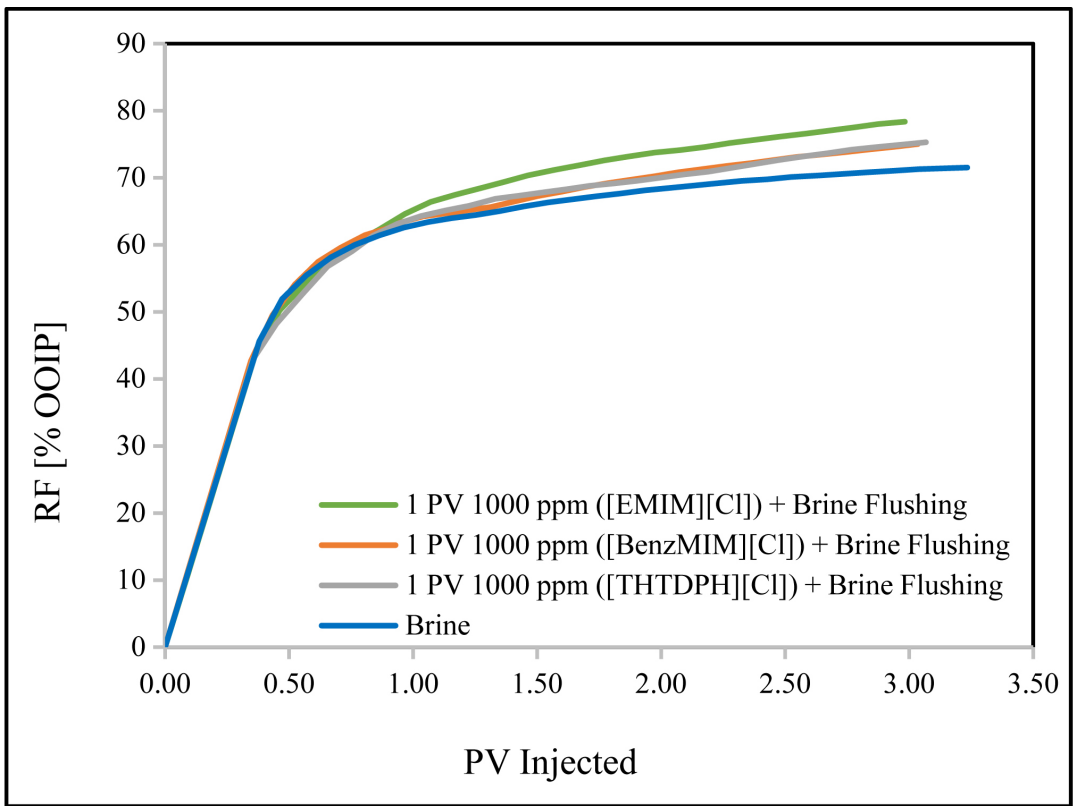

Figure 2. Ionic liquid type effect on the recovery factor. 


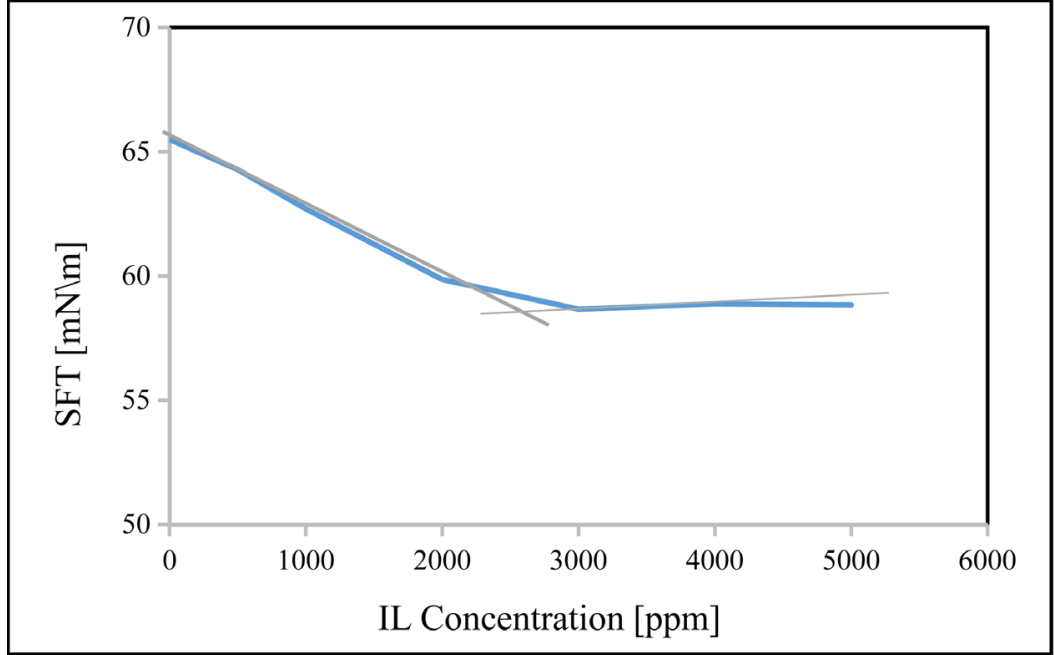

Figure 3. ([EMIM][Cl]) effect on Displacing phase SFT.

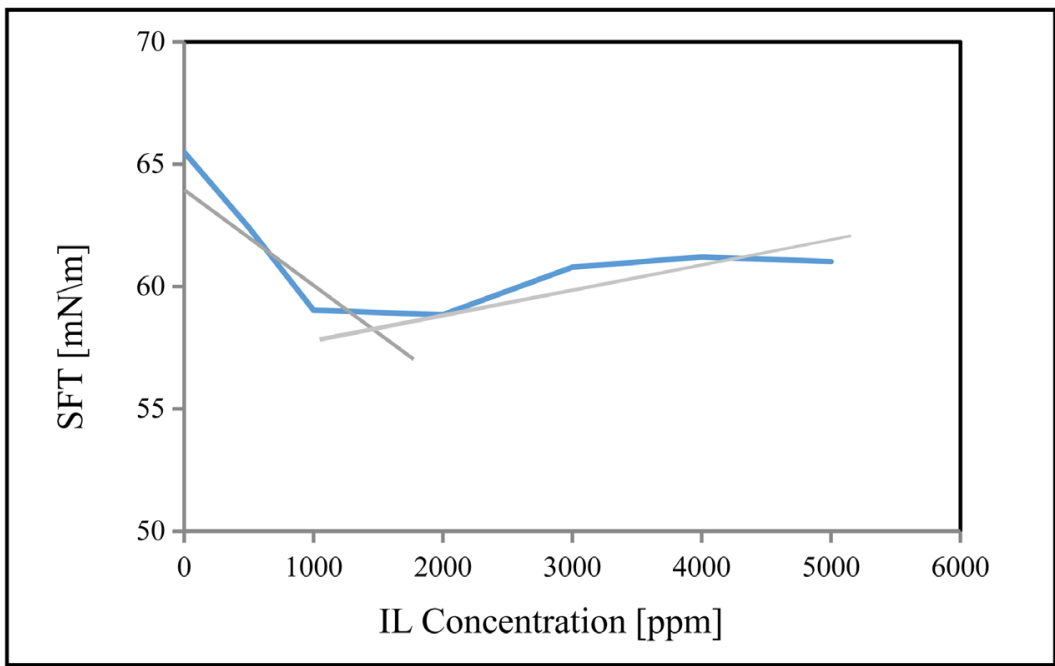

Figure 4. ([BenzMIM] $[\mathrm{Cl}])$ effect on Displacing phase SFT.

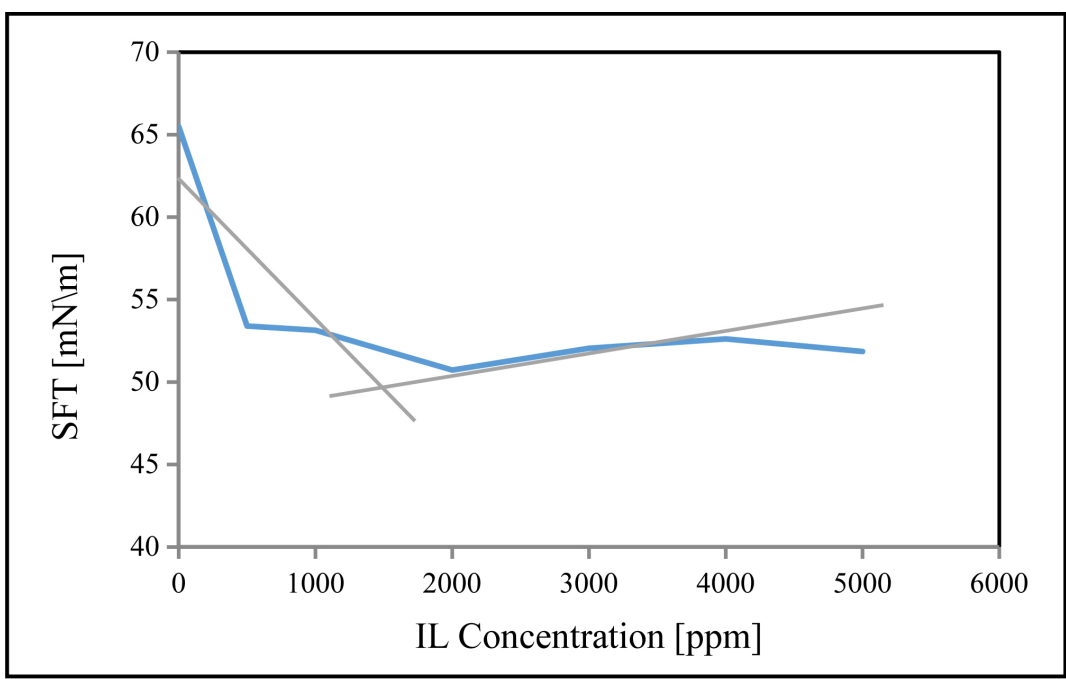

Figure 5. [THTDPh][Cl] effect on Displacing phase SFT. 
Table 4. Properties of IL Mixtures at $1000 \mathrm{ppm}$.

\begin{tabular}{cccc}
\hline IL Type & SFT $[\mathrm{mN} / \mathrm{m}]$ & $\mu[\mathrm{cP}]$ & $\mathrm{pH}$ \\
\hline$[$ EMIM] $[\mathrm{Cl}]$ & 62.701 & 1.341 & 7.02 \\
{$[$ BenzMIM][Cl] } & 59.033 & 1.301 & 7.43 \\
{$[$ THTDPh] $[\mathrm{Cl}]$} & 53.141 & 1.204 & 7.87 \\
\hline
\end{tabular}

after which the values grow slightly. Evidently, $1500 \mathrm{ppm}$ of [BenzMIM][Cl] and [THTDPh] $[\mathrm{Cl}]$ in the mixture produces the highest SFT reduction and it is considered as the CMC value of both ILs.

To investigate the effect of the ILs' CMC on extracting more oil, the CMC for each of these ILs was mixed with brine and injected into the sand pack. The flooding procedure was similar to the optimum scenario obtained from the previous experiments. As presented in Figure 6, the results showed that the effectiveness of adding the CMC of the ILs [EMIM][Cl], [BenzMIM][Cl], and [THTDPh] $[\mathrm{Cl}])$ to brine and flooding the mixture into the sand packs, more oil was able to be extracted than when $1000 \mathrm{ppm}$ of the same ILs mixtures were injected. The additional RF values of injecting the CMC of [EMIM] [Cl], [BenzMIM] $[\mathrm{Cl}]$ and [THTDPh] $[\mathrm{Cl}]$ were 1.74 [\% OOIP], 2.50 [\% OOIP], and 1.41 [\% OOIP], respectively. This enhancement of oil recovery could be due to the reduction in SFT and slight increase in viscosity as presented in Table 5. Overall, the results indicate that using the CMC of ILs and when mixed with brine was efficient in improving the RF.

$p H$ Behaviors. The $\mathrm{pH}$ values of the displacing phase mixtures used in this study were measured at room temperature. It is per another study that an increment in increasing [EMIM] [Ac] concentration in the mixtures lead to an increase in the $\mathrm{PH}$ value of the solutions whereas the effect of temperature was minimal [17]. As anticipated, the increase in water content led to declining the $\mathrm{PH}$ values of extraction mixtures. This is presented in the previous Table 4, and Table 5).

Effect of Wettability Alterations on RF: To investigate the effect of ILs on the wettability of the studied sand packs, relative permeability $\left(\mathrm{K}_{\mathrm{ro}} \& \mathrm{~K}_{\mathrm{rw}}\right)$ curves were plotted based on the following four flooding experiments: 3 PVs of CMC values $(2500 \mathrm{ppm}, 1500 \mathrm{ppm}, 1500 \mathrm{ppm})$ of ILs [EMIM][Cl], [BenzMIM][Cl] and [THTDPh] [Cl]) mixtures. They were injected into unconsolidated samples under the same conditions, respectively. As indicated in Figure 7. The total RF values were increasing in the following order: Brine $(73.27[\%$ OOIP $])<[$ THTDPh $][\mathrm{Cl}]$ $(79.21[\%$ OOIP $])<[$ BenzMIM] $[\mathrm{Cl}](80.01[\%$ OOIP] $)<$ [EMIM] [Cl] $(82.67[\%$ OOIP]). These differences in RF values could be due to the differential impact of ionic liquids on wettability. The $\mathrm{K}_{\mathrm{ro}}$ and $\mathrm{K}_{\mathrm{rw}}$ during these runs were measured by using the relative permeability graphical technique. This method was elaborated by Jones and Roszelle [18]. Relative permeability curves, as presented in Figure 8, clearly show that the maximum shift in $\mathrm{K}_{\mathrm{ro}}$ and $\mathrm{K}_{\mathrm{rw}}$ intersection $\left(\mathrm{S}_{\mathrm{w}}=0.82, \mathrm{~K}_{\mathrm{ro}}\right.$ and $\left.\mathrm{K}_{\mathrm{rw}}=0.08\right)$ was obtained after flooding $3 \mathrm{PV}$ of $1500 \mathrm{ppm}$ [BenzMIM][Cl]. 


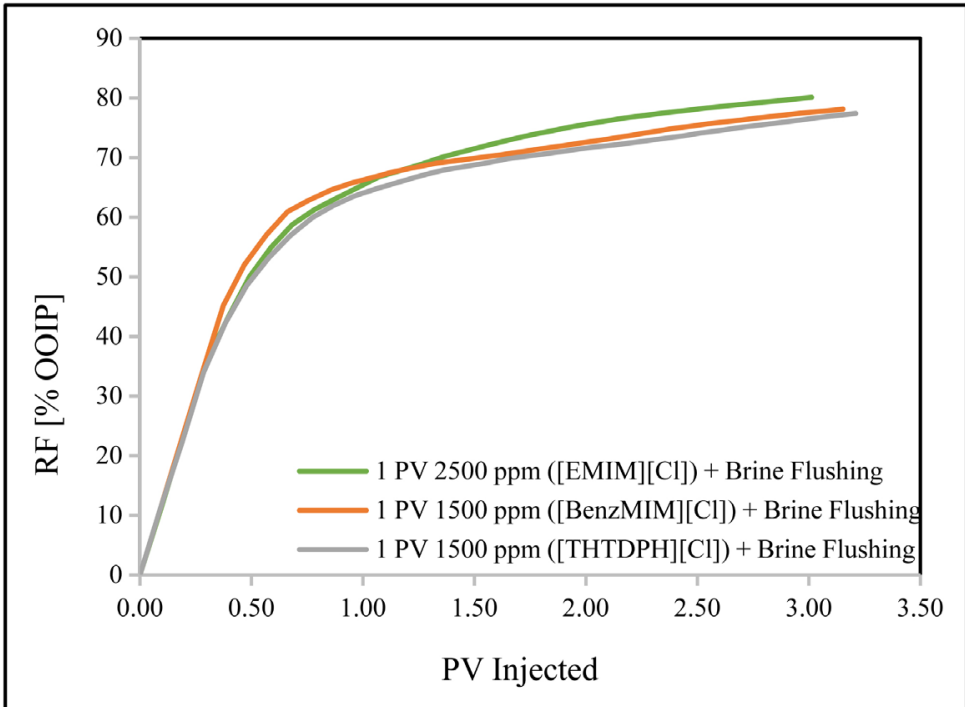

Figure 6. Effect of CMC of Ionic liquids on RF.

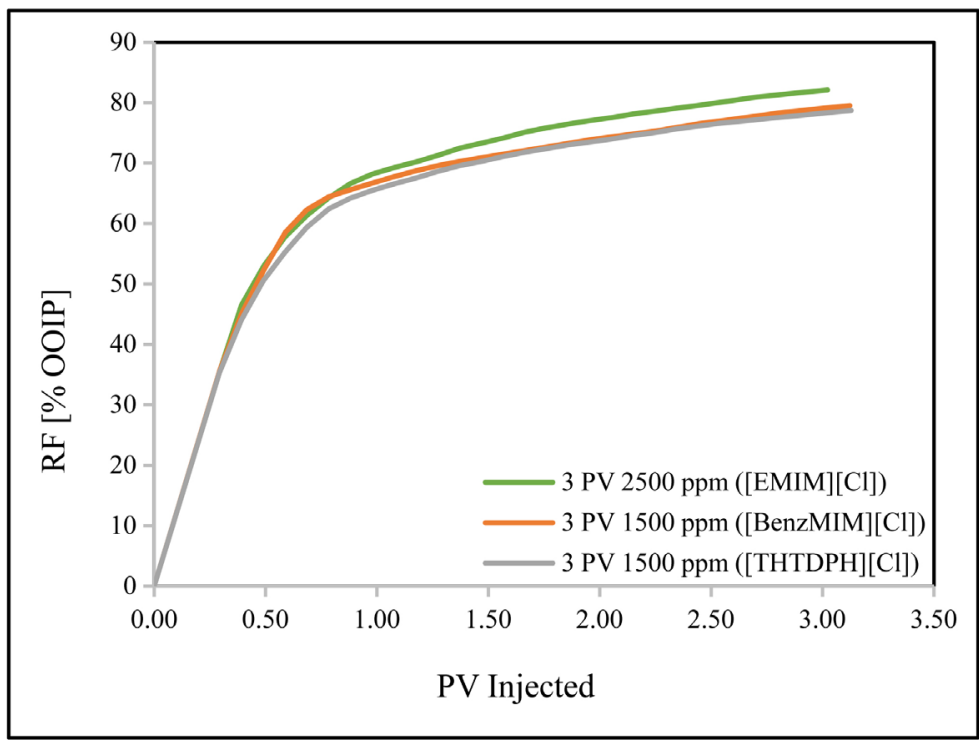

Figure 7. Effect of CMC Ionic liquids on RF in Continuous Secondary Recovery Mode.

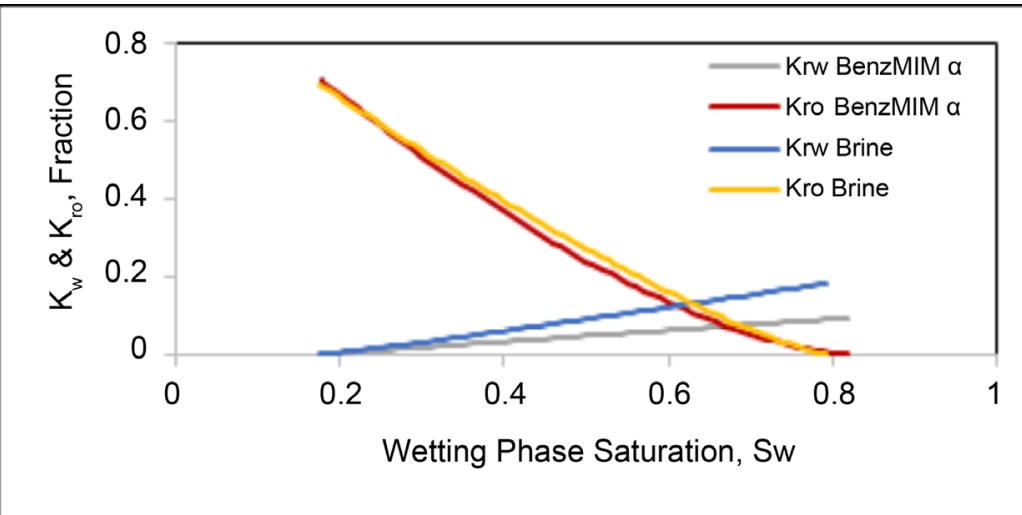

Figure 8. Relative permeability curve, Brine and [BenzMIM][Cl] Solution. 
Table 5. Properties of ILs Mixtures at CMC.

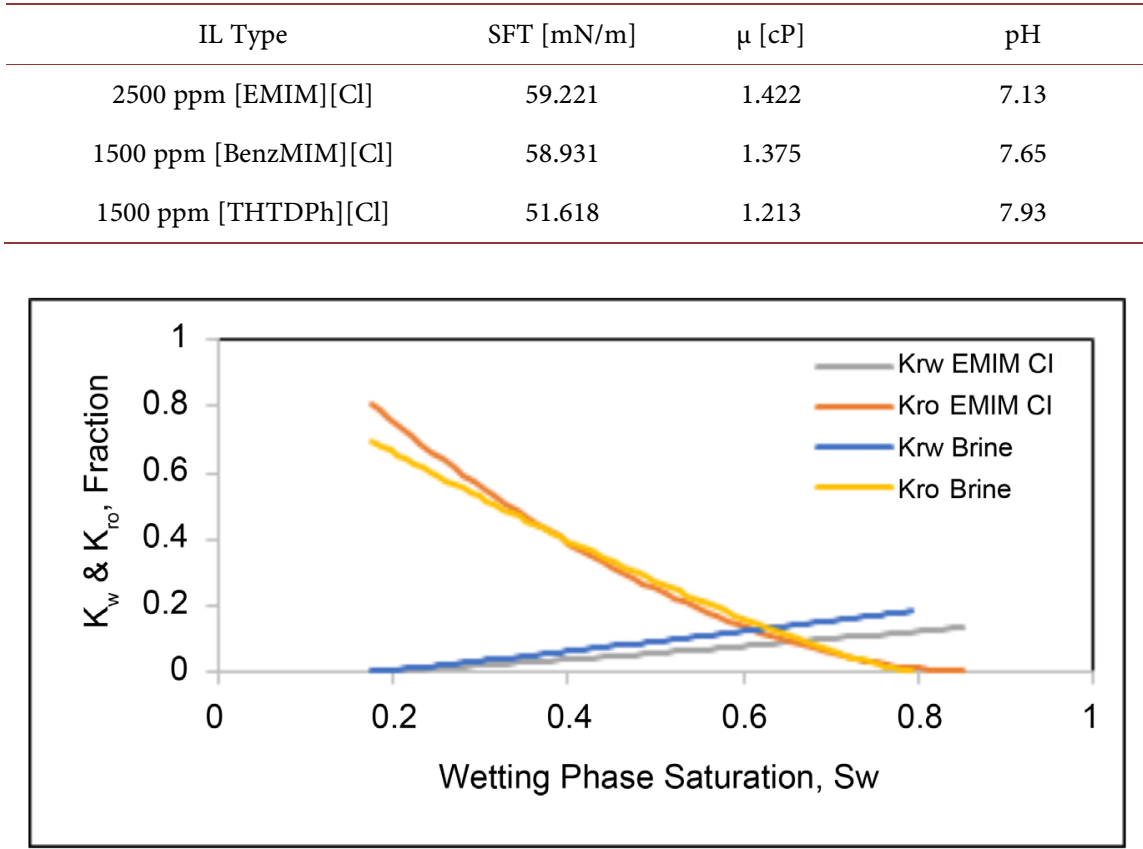

Figure 9. Relative permeability curve, Brine and [EMIM][Cl] Solution.

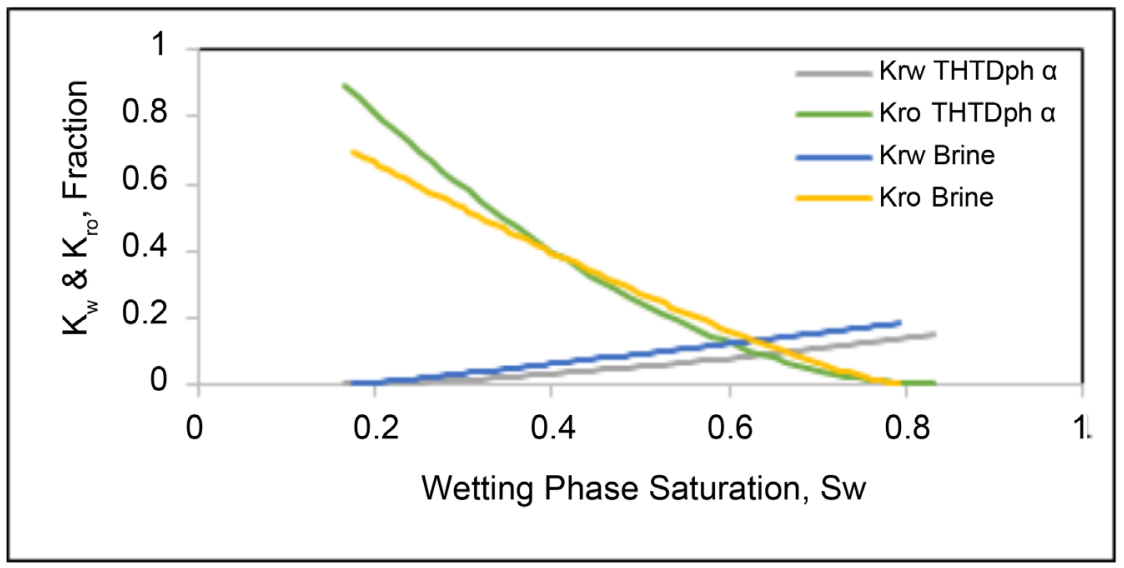

Figure 10. Relative permeability curve, Brine and [THTDPh][Cl] Solution.

The intersection point of the relative permeability curves was reduced further with the injection of $2500 \mathrm{ppm}$ of [EMIM][Cl] mixture, and the intersection point between the $\mathrm{K}_{\mathrm{ro}}$ and krw curves had a $\mathrm{S}_{\mathrm{w}}$ value of 0.66 and 0.10 for both $\mathrm{K}_{\mathrm{ro}}$ and $\mathrm{K}_{\mathrm{rw}}$, as shown in Figure 9. The minimum shift to the right occurred when $1500 \mathrm{ppm}$ of [THTDPh][Cl] mixture was injected and the intersection point between the $\mathrm{K}_{\mathrm{ro}}$ and $\mathrm{K}_{\mathrm{rw}}$ curves had a $\mathrm{S}_{\mathrm{w}}$ value of 0.64 and 0.09 for both $\mathrm{K}_{\mathrm{ro}}$ and $\mathrm{K}_{\mathrm{rw}}$, as shown in Figure 10. From two phases, water oil relative permeability as a function of water saturation, there is an inverse proportion relation between rock water wetness and residual saturation when IL solution flooding is applied as compared to brine flooding. This proves that enhancement in the RF results of this study is due to wettabiltity alteration mechanism as well. 


\section{Conclusions}

The following conclusions were reached based on the experimental results obtained in this study:

1) ILs proved to be efficient when used to enhance medium oil recovery. It is evident that the efficiency of ILs depends on the IL types and concentration.

2) Regarding IL concentration, it was observed that the RF increased as the concentration of IL in the displacing phase increased. Moreover, the optimum concentration depended on the type of IL.

3) In this study, it was found that $[\mathrm{EMIM}][\mathrm{Cl}]$ is the most effective ionic liquid for enhancing medium oil recovery in comparison with the other three ILs.

4) The oil recovery was increased when the ionic liquids were added to the displacing phase due to reduction in mobility ratio and surface tensions of displacing fluids. Additionally, the ionic liquids used had the ability to improve the wettability of the rocks to become more water wet.

\section{Conflicts of Interest}

The authors declare no conflicts of interest regarding the publication of this paper.

\section{References}

[1] Green, D.W. and Willhite, G.P. (1998) Enhanced Oil Recovery. Henry L. Doherty Memorial Fund of AIME. Society of Petroleum Engineers, Richardson, TX.

[2] Huddleston, J.G., Willauer, H.D., Swatloski, R.P., Visser, A.E. and Rogers, R.D. (1998) Room Temperature Ionic Liquids as Novel Media for "Clean" Liquid-Liquid Extraction. Chemical Communications, 16, 1765-1766. https://doi.org/10.1039/A803999B

[3] Kelkar, M.S. and Maginn, E.J. (2007) Effect of Temperature and Water Content on the Shear Viscosity of the Ionic Liquid 1-Ethyl-3-Methylimidazolium Bis (Trifluoromethanesulfonyl) Imide as Studied by Atomistic Simulations. The Journal of Physical Chemistry B, 111, 4867-4876. https://doi.org/10.1021/jp0686893

[4] Lago, S., Francisco, M., Arce, A. and Soto, A. (2013) Enhanced Oil Recovery with the Ionic Liquid Trihexyl (Tetradecyl) Phosphonium Chloride: A Phase Equilibria Study at $75^{\circ}$ C. Energy \& Fuels, 27, 5806-5810. https://doi.org/10.1021/ef401144z

[5] Domańska, U. and Królikowska, M. (2010) Effect of Temperature and Composition on the Surface Tension and Thermodynamic Properties of Binary Mixtures of 1-Butyl-3-Methylimidazolium Thiocyanate with Alcohols. Journal of Colloid and Interface Science, 348, 661-667. https://doi.org/10.1016/j.jcis.2010.04.060

[6] Kumar, B. (2012) Effect of Salinity on the Interfacial Tension of Model and Crude Oil Systems.

[7] Kopczynska, A. (2007) Polymeric Surfaces and Their True Surface Tension in Solids and Melts. Journal of Materials Education, 29, 325.

[8] Khan, M.Y., Samanta, A., Ojha, K. and Mandal, A. (2008) Interaction between Aqueous Solutions of Polymer and Surfactant and Its Effect on Physicochemical Properties. Asia-Pacific Journal of Chemical Engineering, 3, 579-585. https://doi.org/10.1002/apj.212

[9] Hezave, A.Z., Raeissi, S. and Lashkarbolooki, M. (2012) Estimation of Thermal 
Conductivity of Ionic Liquids Using a Perceptron Neural Network. Industrial \& Engineering Chemistry Research, 51, 9886-9893. https://doi.org/10.1021/ie202681b

[10] Rodríguez-Escontrela, I., Rodríguez-Palmeiro, I., Rodríguez, O., Arce, A. and Soto, A. (2016) Characterization and Phase Behavior of the Surfactant Ionic Liquid Tributylmethylphosphonium Dodecylsulfate for Enhanced Oil Recovery. Fluid Phase Equilibria, 417, 87-95. https://doi.org/10.1016/j.fluid.2016.02.021

[11] Anderson, W. (1986) Wettability Literature Survey-Part 2: Wettability Measurement. Journal of Petroleum Technology, 38, 1246-1262. https://doi.org/10.2118/13933-PA

[12] Bin-dahbag, M.S., Al Quraishi, A.A., Benzagouta, M.S., Kinawy, M.M., Al Nashef, I.M. and Al, E. (2014) Experimental Study of Use of Ionic Liquids in Enhanced Oil Recovery.

[13] Mohammed, M.A. and Babadagli, T. (2016) Experimental Investigation of Wettability Alteration in Oil-Wet Reservoirs Containing Heavy Oil. SPE Reservoir Evaluation \& Engineering. https://doi.org/10.2118/170034-PA

[14] Hezave, A.Z., Dorostkar, S., Ayatollahi, S., Nabipour, M. and Hemmateenejad, B. (2013) Investigating the Effect of Ionic Liquid (1-Dodecyl-3-Methylimidazolium Chloride ([C $12 \mathrm{mim}][\mathrm{cl}]))$ on the Water/Oil Interfacial Tension as a Novel Surfactant. Colloids and Surfaces A: Physicochemical and Engineering Aspects, 421, 63-71. https://doi.org/10.1016/j.colsurfa.2012.12.008

[15] Fathi, S.J., Austad, T. and Strand, S. (2011) Water-Based Enhanced Oil Recovery (EOR) by "Smart Water": Optimal Ionic Composition for EOR in Carbonates. Energy \& Fuels, 25, 5173-5179. https://doi.org/10.1021/ef201019k

[16] Alarbah, A., Shirif, M. and Shirif, E. (2017) Efficiency of Ionic Liquid 1-Ethyl-3-Methyl-Imidazolium Acetate ([EMIM][Ac]) in Enhanced Medium Oil Recovery. Advances in Chemical Engineering and Science, 7, 291. https://doi.org/10.4236/aces.2017.73022

[17] Ober, C.A. and Gupta, R.B. (2012) pH Control of Ionic Liquids with Carbon Dioxide and Water: 1-Ethyl-3-Methylimidazolium Acetate. Industrial \& Engineering Chemistry Research, 51, 2524-2530. https://doi.org/10.1021/ie201529d

[18] Jones, S. and Roszelle, W. (1978) Graphical Techniques for Determining Relative Permeability from Displacement Experiments. Journal of Petroleum Technology, 30, 807-817. https://doi.org/10.2118/6045-PA 